\title{
Integrated therapy for HIV and tuberculosis
}

\author{
Weerawat Manosuthi', Surasak Wiboonchutikul ${ }^{1}$ and Somnuek Sungkanuparph ${ }^{2^{*}}$
}

\begin{abstract}
Tuberculosis (TB) has been the most common opportunistic infection and cause of mortality among HIV-infected patients, especially in resource-limited countries. Clinical manifestations of TB vary and depend on the degree of immunodeficiency. Sputum microscopy and culture with drug-susceptibility testing are recommended as a standard method for diagnosing active TB. TB-related mortality in HIV-infected patients is high especially during the first few months of treatment. Integrated therapy of both HIV and TB is feasible and efficient to control the diseases and yield better survival. Randomized clinical trials have shown that early initiation of antiretroviral therapy (ART) improves survival of HIV-infected patients with TB. A delay in initiating ART is common among patients referred from TB to HIV separate clinics and this delay may be associated with increased mortality risk. Integration of care for both HIV and TB using a single facility and a single healthcare provider to deliver care for both diseases is a successful model. For TB treatment, HIV-infected patients should receive at least the same regimens and duration of TB treatment as HIV-uninfected patients. Currently, a 2-month initial intensive phase of isoniazid, rifampin, pyrazinamide, and ethambutol, followed by 4 months of continuation phase of isoniazid and rifampin is considered as the standard treatment of drugsusceptible TB. ART should be initiated in all HIV-infected patients with TB, irrespective of CD4 cell count. The optimal timing to initiate ART is within the first 8 weeks of starting antituberculous treatment and within the first 2 weeks for patients who have CD4 cell counts $<50$ cells $/ \mathrm{mm}^{3}$. Non-nucleoside reverse transcriptase inhibitor (NNRTI)-based ART remains a first-line regimen for HIV-infected patients with TB in resource-limited settings. Although a standard dose of both efavirenz and nevirapine can be used, efavirenz is preferred because of more favorable treatment outcomes. In the settings where raltegravir is accessible, doubling the dose to $800 \mathrm{mg}$ twice daily is recommended. Adverse reactions to either antituberculous or antiretroviral drugs, as well as immune reconstitution inflammatory syndrome, are common in patients receiving integrated therapy. Early recognition and appropriate management of these consequences can reinforce the successful integrated therapy in HIV-infected patients with TB.
\end{abstract}

Keywords: HIV, Tuberculosis, Treatment, Integrated therapy

\section{Background}

Tuberculosis (TB) is one of the most common opportunistic infections among HIV-infected patients especially in resource-limited countries worldwide. In Africa and Asia, TB is also the most common cause of mortality in HIV-infected population [1]. HIV changes the clinical presentation of TB from a slowly progressing disease to one with a high mortality rate. A prospective multicenter

\footnotetext{
*Correspondence: somnuek.sun@mahidol.ac.th

${ }^{2}$ Division of Infectious Diseases, Department of Medicine, Faculty

of Medicine Ramathibodi Hospital, Mahidol University, 270 Rama 6 Road,

Bangkok 10400, Thailand

Full list of author information is available at the end of the article
}

cohort has clearly demonstrated that the risk of $\mathrm{TB}$ is associated with increasing immunodeficiency and $\mathrm{TB}$ occurrence significantly increases the risk of mortality [2]. Optimal treatment of TB with good patient compliance can lead to the successful treatment and reduction of mortality [3].

Antiretroviral therapy (ART) has proven to have a great impact on survival rates among HIV-infected patients with TB $[2,4,5]$. Simultaneous treatment of both TB and HIV is required for HIV-infected patients presenting with TB. In addition, patients in resource-limited settings with low CD4 cell counts, continue to present late to healthcare providers. New episodes of opportunistic 
infections may develop within the first few months after ART and TB presents most frequently in this situation $[6,7]$. An integrated therapy of both HIV and TB based on the current evidence of studies from both diseases has shown to be feasible and efficient in controlling the diseases and yields better survival in various clinical settings. This article focuses on the integrated therapy for HIV-infected patients with active TB and details regarding diagnosis and treatment of TB, initiation of ART, management of drug-drug interaction, overlapping toxicities of antituberculous and antiretroviral drugs, as well as $\mathrm{TB}$ immune reconstitution inflammatory syndrome are discussed.

\section{Clinical manifestations of TB in HIV-infected patients}

TB among HIV-infected patients is resulted from reactivation of past infection or new infection of Mycobacterium tuberculosis [8]. Clinical manifestations are varying from classic symptoms of prolonged fever, hemoptysis, productive cough, weight loss, or night sweat to minimal or nonspecific symptoms [9]. A previous study in Southeast Asia had reported that the presence of cough of any duration, fever of any duration, or night sweats lasting 3 or more weeks in the preceding 4 weeks was $93 \%$ sensitive and $36 \%$ specific for tuberculosis [10]. The clinical features of TB depend on the degree of immunodeficiency. The presentation of pulmonary TB in AIDS patients may be atypical and unusual [11]. TB patients with CD4 cell counts less than 200 cells $/ \mathrm{mm}^{3}$ are likely to have hilar or mediastinal adenopathy on chest radiographs, but less likely to have cavitary lesion [12]. Miliary infiltrate is commonly found on chest radiographs among AIDS patients [13]. Normal radiographs can be found in $14-22 \%$ of HIV-associated TB $[14,15]$.

Extrapulmonary $\mathrm{TB}$ is common in HIV-infected patients and can be seen in up to $60 \%$ of HIV-infected patients with TB $[16,17]$. Patients with lower CD4 cell counts have the higher risk of extrapulmonary $\mathrm{TB}$ and mycobacteremia [18]. The frequent forms of extrapulmonary disease are lymphadenitis, disseminated or bloodstream infection, and TB pleuritis [17-19]. TB meningitis is the most severe form of TB. High mortality rate is observed in spite of ART [20]. Other extrapulmonary sites of HIV-associated TB include bone and joint, skin and soft tissue, pericardium, liver, spleen, kidney, gastrointestinal, and genitourinary tract [21].

\section{Diagnosis of TB in HIV-infected patients}

A definitive diagnosis of TB is confirmed by culturing $M$. tuberculosis organisms from a specimen obtained from the patient. For pulmonary TB, sputum-smear for ZiehlNeelsen staining is fast, inexpensive, and a highly specific method. However, the sensitivity of direct microscopy in searching for acid-fast bacilli is variable from 31 to $80 \%$ according to a previous review [22]. Studies from Africa found that patients with concurrent HIV and TB infection have a higher frequency of smear-negative TB than those of HIV-uninfected patients [23]. Concentrating the specimen provided an additional positive yield of $36 \%$ for the sputum-negative patients in a high HIVprevalent area [24]. Currently, sputum microscopy and culture in liquid medium with subsequent drug-susceptibility testing are recommended as standard method for diagnosing active TB [25]. Nevertheless, the use of solid culture medium may be more cost-effective in resourcelimited countries. In systematic review, the mean time to detection with Löwenstein-Jensen cultures was 24 days, whereas automated mycobacterial liquid culture systems had a mean time to detection of 15 days [26]. Drug resistant TB substantially reduces survival in HIV-infected patients with TB $[27,28]$. Early detection and optimal treatment of drug resistant TB are crucial. Susceptibility testing of $M$. tuberculosis should be performed wherever this test is available.

Beyond sputum microscopy, new molecular diagnostic tests provide a rapid diagnosis of active TB. Xpert MTB/RIF, the automated real-time nucleic acid amplification assay, is endorsed for the diagnosis of pulmonary TB by World Health Organization [29]. Overall pooled sensitivity is $88 \%$ and a pooled specificity is $99 \%$ when used as an initial diagnostic test replacing smear microscopy. However, the pooled sensitivity of Xpert MTB/RIF decreases to $79 \%$ for HIV-infected patients [29]. Other molecular tests, including MTBDRplus and LightCycler Mycobacterium Detection have demonstrated specificities of more than $97 \%$, but the sensitivities reduced by $6 \%$ when comparing with Xpert MTB/RIF test in HIVinfected patients with pulmonary TB [30]. A tuberculin skin test and an interferon-gamma release assay are unable to distinguish latent TB from active disease [8]. Usefulness of lipoarabinomannan (LAM) antigen-detection assay for the diagnosis of active TB in HIV-infected patients has recently been found to decrease mortality [31-33]. The implementation of LAM testing is likely to offer the greatest benefit in healthcare facilities where diagnostic resources are scarce and patients present with severe illness, advanced immunosuppression, and an inability to self-expectorate sputum [33].

For extrapulmonary disease, Ziehl-Neelsen stain helps to detect acid-fast bacilli in tissues and smears. However, the conventional smear microscopy has limited diagnostic value with low sensitivity [34,35]. A recent metaanalysis reported that Xpert MTB/RIF has an overall sensitivity of $83.1 \%$ and a pooled specificity of $98.7 \%$ for the diagnosis of extrapulmonary TB [36]. Xpert MTB/RIF is a sensitive diagnostic test for TB detection in lymph 
node samples $(83.1 \%)$ and for the detection of TB meningitis $(80.5 \%)$ while only $46.4 \%$ pooled sensitivity was shown in testing with pleural fluid [36]. In tissue samples other than a lymph node, a pooled estimate of sensitivity and specificity were 81.2 and $98.1 \%$, respectively [37]. However, direct methods sometimes fail to detect mycobacterium in the clinical specimens. Indirect methods sometimes help with diagnosis of extrapulmonary $\mathrm{TB}$. In endemic $\mathrm{TB}$ areas, presence of granulomatous inflammation with or without caseation on histopathology is suggestive for TB [38]. Another indirect test such as adenosine deaminase (ADA) test has considerable evidence to support its use for diagnosis of pleural TB and to a slightly lesser extent for TB meningitis [39].

\section{Integrated therapy of HIV and TB: general concept}

Integrated therapy is crucial for HIV-infected patients with TB. The two diseases, HIV and TB, must be managed simultaneously. TB-related mortality in HIVinfected patients is high during the first few months of TB treatment [1]. Additionally, evidence from randomized clinical trials and systemic review has shown that early initiation of ART improves survival of HIV-infected patients with TB [20, 40-46]. Managing the two diseases more effectively during this critical period is therefore essential to improve the patients' survival and quality of life. The World Health Organization guidelines have recommended ART initiation during this time period [47-49]. However, ART initiation is often delayed due to various factors such as patient characteristics, overlapping drug toxicities, fear of clinicians or patients, and policies of local HIV and TB programs. Delay in initiating ART is more common among patients referred from TB to HIV separate clinics [50]. Delays in the initiation of ART in HIV-infected patients with TB, particularly those with very low CD4 cell counts, are associated with increased mortality risk.

The successful models of integration of care for both HIV and TB mainly use a single facility such as an integrated HIV/TB care center and a single health care provider delivering care for both diseases [51, 52]. The advantages include providing faster initiation of ART treatment for HIV-infected patients with TB, holistic evaluation of the patients, and practical management when patients encounter adverse drug effects. In addition, this model in resource-limited settings is also more feasible to set up, maintain, and train the healthcare providers. A systematic review has demonstrated that integrated care of HIV and TB may overcome challenges such as losing patients to follow-up during the referral process between TB and HIV clinics, burdening patients with increased travel costs and additional time spent in clinics [53]. Interventions for improving adherence and social support can also better reinforce this approach. Integrated therapy for both HIV and TB by the same team of healthcare providers may provide better clinical outcomes and use limited resource more efficiently.

\section{Combination therapy of TB in general population}

Streptomycin became the first effective treatment of TB in 1946, but the treatment was eventually a failure with frequent emergence of streptomycin resistance. The strategy to overcome the resistance problem with combination therapy of streptomycin, aminosalicylic acid, and isoniazid was reported in the 1950s. However, the treatment period was not less than 1 year $[54,55]$. After the discovery of rifampin and pyrazinamide, studies showed that the duration of treatment could be shortened to only 6 months by the inclusion of rifampicin and pyrazinamide in the regimen $[56,57]$. Currently, a 2-month initial intensive phase with isoniazid, rifampin, and pyrazinamide, followed by 4 months of a continuation phase with isoniazid and rifampin is considered as the standard treatment of drug-susceptible TB [58-60]. Ethambutol is usually recommended as the fourth drug in the intensive phase to prevent unrecognized resistance to one of the three core drugs [61]. Recent clinical trials in shortening TB treatment duration to 4 months by moxifloxacin- or gatifloxacin-containing regimens demonstrated a higher relapse rate than those of standard regimen [62-64].

The multidrug initial intensive phase is to reduce the bacillary load by killing mycobacteria rapidly and to prevent the emergence of drug resistance. The continuation phase of therapy is given to kill the slowly replicating or non-replicating subpopulation. Isoniazid provides bactericidal activity by initially killing about $95 \%$ of bacilli during the first 2 days of treatment. Its bactericidal role is then replaced by rifampicin and pyrazinamide. Rifampicin and pyrazinamide are also responsible for the sterilizing activity by killing persistent or non-replicating organisms [55, 65]. A combination of at least two fully effective drugs was necessary to prevent the emergence of resistance [54].

Pulmonary and extrapulmonary TB should be treated with the same regimens [58]. Six months of standard therapy is generally considered adequate for most forms of extrapulmonary tuberculosis. However, treatment duration may need to be extended for central nervous system and skeletal tuberculosis. Although the optimal duration of therapy cannot be defined, the 9-12 months duration is recommended for the treatment of TB meningitis because of serious risk of disability and mortality and for the treatment of TB of bone and joints because of the difficulties of assessing treatment response [58-60]. Adjunctive corticosteroids reduce the risk of death or disabling residual neurological deficit in patients with 
tuberculous meningitis [66], and may be beneficial in those with tuberculous pericarditis [67]. An intensified regimen for TB meningitis that includes both a higher dose of oral rifampicin and the addition of levofloxacin to the standard regimen does not provide benefit on reducing overall mortality [68].

\section{Treatment of TB in HIV-infected patients}

The principles for treatment of active $\mathrm{TB}$ disease in HIV-infected patients are the same as those for HIVuninfected patients. TB treatment is the priority. The regimens should include rifampicin and isoniazid [69, 70]. The 6-month duration with standard regimen among HIV-infected patients showed similar cure and treatment failure rates as in HIV-uninfected patients [71-73]. However, a meta-analysis on treatment of active TB in HIV-infected patients suggested that longer duration of rifamycin therapy (at least 8 months) were associated with a lower risk of TB relapse [74]. Intermittent intensive-phase treatment was associated with increased odds of treatment failure [75]. ART was found to lower the risk of TB relapse [74]. Studies to assess duration of rifamycin-based TB treatment and dosing schedule in patients receiving ART are needed for further evaluation. Currently, the World Health Organization's guideline for the treatment of TB recommends that HIV-infected patients should, as a minimum, receive the same duration and daily dosing of TB treatment as HIV-uninfected patients. ART should be initiated in all HIV-infected with TB patients, irrespective of CD4 cell count [58].

Rifabutin induces CYP3A activity at a lesser magnitude than rifampicin and it may therefore be a more appropriate option for co-administration with many antiretroviral drugs, including PIs [76]. Of noted, PIs increase the dose of rifabutin. Thus, rifabutin dosage required adjustment to minimize rifabutin-associated toxicity, including neutropenia, uveitis, and liver toxicity [59]. A concern with rifabutin $150 \mathrm{mg}$ thrice weekly is that rifabutin under exposure may result in acquired rifamycin resistance. Some experts recommend rifabutin at a dose of $150 \mathrm{mg}$ daily when co-administered with any ritonavir-boosted PI $[60,61]$. A recent randomized pharmacokinetic evaluation of different rifabutin doses in African HIV-infected patients with TB and on lopinavir/ritonavir-based ART has demonstrated that a daily $150 \mathrm{mg}$ dose of rifabutin in combination with lopinavir/ritonavir safely maintained rifabutin plasma concentrations [77]. To date, the replacement of rifampicin by rifabutin for first-line treatment of TB is not supported by the current evidence [78].

\section{ART in HIV-infected patients with TB}

The optimal timing to commence ART in HIV-infected patients with $\mathrm{TB}$ is relatively complex. It must balance the risk of morbidity and mortality in very advanced HIV disease with the potential occurrence of additive toxicities, drug-drug interactions, and TB-associated immune reconstitution inflammatory syndrome (IRIS). The current World Health Organization guidelines recommend that ART should be started as soon as possible "within the first 8 weeks" of starting antituberculous treatment and within the first 2 weeks for patients who have CD4 cell counts less than 50 cells $/ \mathrm{mm}^{3}$ [47-49]. The results from randomized control trials have been published over the past 5 years [40-44]. They have shown the same trend of survival benefit of concurrent ART during TB treatment. In addition, ART initiation within the first 2 weeks of TB treatment is beneficial in patients with advanced HIV disease, i.e., CD4 cell count $<50$ cells $/ \mathrm{mm}^{3}$ [40-44], although it is associated with a twofold higher frequency of TB IRIS [45]. TB IRIS is generally manageable and survival benefits of early ART in this group outweigh the risk of TB IRIS.

In patients with $\mathrm{CD} 4$ cell counts higher than 50 cells/ $\mathrm{mm}^{3}$, evidence is insufficient to support or refute a survival benefit conferred by early ART initiation [45]. Recently, a randomized control study in co-infected HIV and TB patients with high CD4 cell counts showed no difference of mortality between early and deferred ART on the unfavorable composite endpoint of death, tuberculosis treatment failure, and recurrence [46]. Therefore, patients with less immune deficiency, i.e., CD4 cell counts higher than 50 cells $/ \mathrm{mm}^{3}$, ART may be deferred until completion of intensive phase of TB treatment without compromising survival. In addition, a study in HIV-associated TB meningitis showed that immediate ART was not associated with reduced 9-month mortality, when compared to deferred ART initiation [20]. The adverse events were significantly more frequently found in both overall and during the first 2 months of treatment in immediate versus deferred ART arm [20]. Nonetheless, treatment guidelines in the resource-rich setting recommends to start ART as soon as possible with close monitoring and prompt management of adverse reactions and central nervous system IRIS [69]. Thus, caution in early ART initiation is warranted in patients with $\mathrm{TB}$ meningitis. Table 1 summarizes all randomized control trials of the timing to initiate ART during TB treatment.

A rifamycin-containing antituberculous regimen is crucial in the treatment of drug-sensitive TB. The regimens which do not contain rifampicin during the continuation phase are significantly inferior to the standard 6-month regimen in newly diagnosed smear-positive pulmonary TB [79]. Rifapentine, a long-acting rifamycin, is not recommended for TB treatment in HIV-infected patients receiving ART because of significant cytochrome P 450 induction. Both rifampin and rifabutin are less strong 


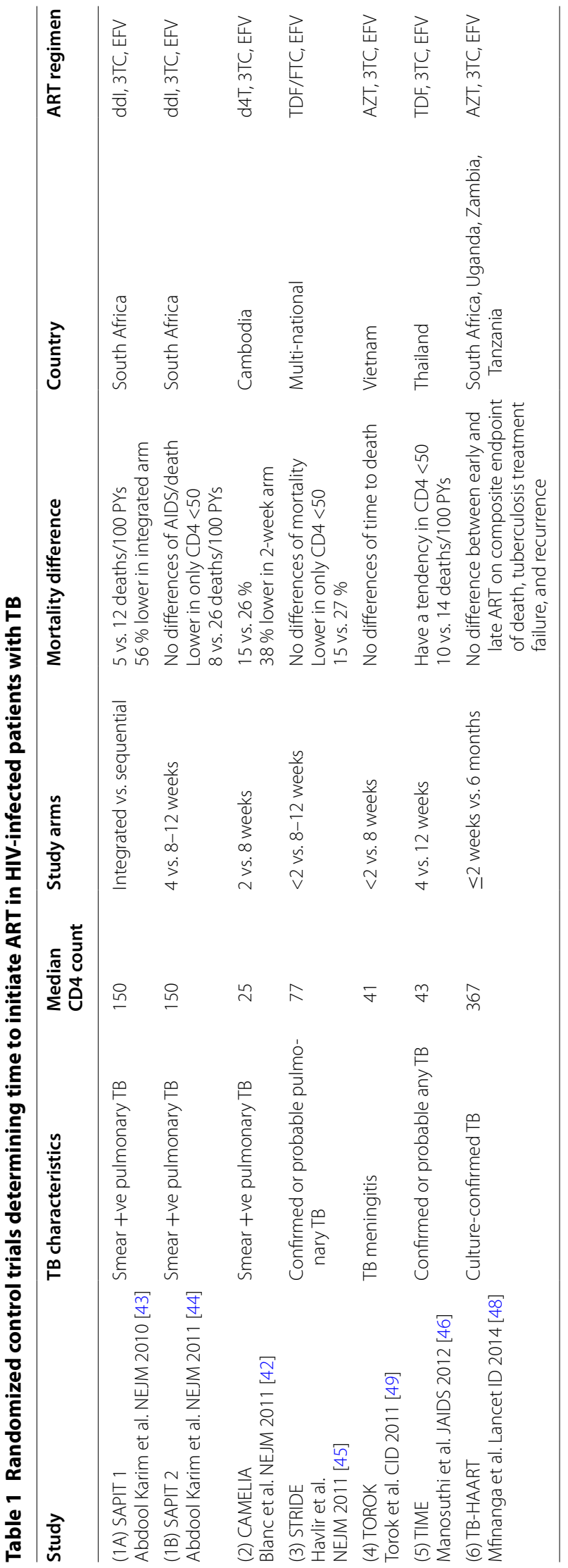


hepatic cytochrome P 450 inducers. However, these two drugs upregulate the uridine diphosphate glucuronosyltransferase 1A1 enzymes [80]. Therefore, they are associated with significant drug-drug interactions in different magnitudes with many antiretroviral drugs, including all protease inhibitors (PIs), non-nucleoside reverse transcriptase inhibitors (NNRTIs), and integrase inhibitors. Despite the problem of drug-drug interactions between rifamycins and antiretroviral drugs, simultaneous treatment of both TB and HIV are required. Co-administration of rifampin and PIs is not recommended owing to significantly decreased plasma concentrations of all PIs and poor treatment outcomes [81-83]. Increasing the dosage of ritonavir or other PIs has resulted in unacceptable rates of liver toxicity and intolerability [84, 85]. A small study of double-dose lopinavir-ritonavir in combination with rifampicin-based antituberculosis treatment in South Africa has shown the favourable outcomes, with $80 \%$ of patients achieving TB treatment success. However, $36 \%$ of patients experienced gastrointestinal toxicity and $12 \%$ had elevated liver enzymes [86].

In many resource-limited settings where $\mathrm{HIV}$ and $\mathrm{TB}$ are epidemic, NNRTI-based ART remains a first-line regimen. Previous studies have shown some effects of rifampicin on the minimal efavirenz concentrations. Some experts recommend increasing the dosage of efavirenz from 600 to $800 \mathrm{mg} /$ day in patients with body weight more than $50 \mathrm{~kg}$ to overcome the drug-drug interactions [87]. Subsequent trials have shown that concomitant use of standard-dose efavirenz at $600 \mathrm{mg} /$ day and rifampicin does not compromise the clinical treatment outcomes [88-92]. However, certain genetic polymorphisms of efavirenz metabolism, i.e., single nucleotide polymorphisms of the hepatic cytochrome P450 isoenzyme 2B6 (CYP2B6) gene, have been associated with high inter-patient variations in its plasma concentrations. The CYP $2 B 6516 \mathrm{G}>\mathrm{T}$ is associated with high plasma concentrations even among patients concurrently receiving rifampicin [93-96]. Given its proven efficacy and simplicity, the use of a standard dose of efavirenz at $600 \mathrm{mg} /$ day combined with two NRTIs is the recommended regimen in antiretroviral-naïve patients who are receiving rifampicin.

Prior studies demonstrated that rifampicin reduces plasma concentrations of nevirapine by 20-55 \% [97-99]. However, virological and immunological responses to nevirapine-based ART when given at a dose of $200 \mathrm{mg}$ twice daily were similar for patients that are and are not receiving rifampin-containing antituberculous treatment [100]. Additionally, a 2-week lead-in period of nevirapine is associated with a higher chance of virological failure owing to subtherapeutic concentration of nevirapine [91]. Non-inferiority of the nevirapine-based ART was not shown in a head-to-head comparison with efavirenzbased ART. With regards to safety, nevirapine at full dose could be a safe, acceptable alternative for patients unable to tolerate efavirenz and other options are not available [101]. A higher dose of nevirapine at $300 \mathrm{mg}$ twice daily to overcome drug-drug interactions is associated with higher rates of liver toxicity [102]. Rifampicin significantly reduces plasma concentrations of rilpivirine and etravirine, thus, these drugs are not recommended to be co-administered with rifampicin [103]. With regards to integrase inhibitor, raltegravir co-administered with rifampicin resulted in lower raltegravir minimum concentration by $61 \%$. Doubling the dose of raltegravir to $800 \mathrm{mg}$ when co-administered with rifampicin can compensate the effect of rifampicin on raltegravir area under the curve but not overcome the effect on concentration at $12 \mathrm{~h}$ after dosing [104].

In the phase II study, high rates of success were achieved at 48 weeks with raltegravir $400 \mathrm{mg}$ twice daily, $800 \mathrm{mg}$ twice daily, or efavirenz $600 \mathrm{mg}$ once daily when used in combination with tenofovir and lamivudine in patients receiving a rifampin-containing $\mathrm{TB}$ treatment [105]. However, further larger and long-term studies remain needed to confirm this finding. Given rifampicin lowers the minimum concentration of raltegravir, doubling the dose of raltegravir to $800 \mathrm{mg}$ twice daily should be an appropriate treatment strategy. Studies examining the concomitant use of dolutegravir and rifampicin are ongoing.

The rapid worldwide scale-up of ART in the resourcelimited settings has led to increasing numbers of patients failing first-line ART. The options for second-line ART after failure with a first-line NNRTI-based regimen generally involve the switch to a PI combined with an alternate NRTI backbone. As aforementioned, the drug-drug interactions between rifampicin and PIs are extensive. Therefore, rifabutin should be an appropriate alternative rifamycin in this setting although clinical data regarding safety and efficacy in the treatment of TB in HIVinfected patients is scanty. However, rifabutin is not available in many countries and it is not produced in fixed dose combination. Thus, an alternative option is using a non-rifamycin anti-TB regimen in HIV-infected patients receiving PIs. Fluoroquinolones such as ofloxacin, levofloxacin, or ciprofloxacin may be used to substitute rifampicin. In addition, a non-rifamycin anti-TB regimen should be given for a period of 9-12 months. The management of HIV-infected patients taking PIs and undergoing treatment for active TB with a non-rifamycin anti-TB regimen should be directed by, or conducted in consultation with, a physician with experience in the care of patients with these two diseases. This care should include close attention to the possibility of TB treatment 
failure, antiretroviral treatment failure, and overlapping toxicities for all drugs used.

\section{Overlapping toxicities of antituberculous and antiretroviral drugs}

Adverse drug reactions occur more frequently among HIV-infected patients with TB who are receiving concurrent treatment of HIV and TB than HIV-uninfected patients $[106,107]$. The common overlapping toxicity profiles include liver toxicity, skin reactions, renal toxicity, and gastrointestinal reactions [108-113]. Table 2 shows the common overlapping adverse events of firstline antituberculous drugs and antiretroviral drugs. These reactions may be complicated and need intensive management in some patients. Early recognition of these adverse events and prompt appropriate management of these problems can lead to successful integrated therapy in HIV-infected patients with TB.

\section{TB IRIS}

TB IRIS may develop among HIV-infected patients who had recently diagnosed active TB or had undiagnosed $\mathrm{TB}$ and subsequently received effective ART. TB IRIS or TB-associated immune recovery disease refers to an inflammatory reaction directed to $M$. tuberculosis antigen presenting at the sites of infection. Two patterns of TB IRIS have been described in the literatures, including paradoxical TB IRIS and unmasking TB IRIS. The paradoxical TB-IRIS is defined as the deterioration of existing TB lesions after recent initiation, re-initiation or switch to more effective ART. The patients with paradoxical TB IRIS typically have clinical improvement or clinical stabilization from receiving antituberculous treatment for a short period of time before initiating ART. The epidemiologic data of paradoxical TB-IRIS are variable, ranging from 8 to $42 \%$ [114-118]. However, a meta-analysis showed that the frequency of paradoxical TB IRIS was $15.7 \%$, with a mortality rate of $3.2 \%$ [119]. The onset of paradoxical TB IRIS typically develops between 1 and 4 weeks after ART commencement and the symptoms lasts for 2-3 months. However, late manifestations of IRIS may present. The common manifestations include high fever, worsening of lymph node enlargement (Fig. 1), and new or worsening of lung infiltration. The neurological TB IRIS may present with cerebral abscess, meningitis, and radiculomyelitis [120,121]. The identified risk factors of paradoxical TB IRIS include low nadir CD4 cell count at ART initiation [117, 122], extrapulmonary or disseminated TB $[116,123]$ and a short period between starting TB treatment and ART [118]. The risk factors associated with death in paradoxical TB IRIS included a low nadir CD4 cell count prior to ART initiation and a shorter period between initiating antituberculous treatment and ART [48, 77].

The second pattern, unmasking TB IRIS, occurs after ART initiation in HIV-infected patients with undiagnosed active TB. The subsequent immune restoration provokes the exaggerated symptoms of TB [124]. Thus, the risk factor of unmasking TB IRIS relates to the efficiency of TB screening and diagnosis of subclinical TB prior to ART initiation. A typical clinical presentation is rapid onset and clinical features of $\mathrm{TB}$ at the site of infection, such as high fever, pneumonitis, and lymphadenitis $[125,126]$. The symptoms may mimic bacterial sepsis.

The consensus case definition of both patterns of $\mathrm{TB}$ IRIS is still debated because they do not provide clear consensus on diagnosis [127-129]. The proposed definition of diagnosis in the resource-limited settings has been published previously by the INSHI group [129]. However, patients with undiagnosed multidrug-resistant TB may mimic the symptoms of paradoxical TB IRIS. Thus, antituberculous drug resistance should be excluded in all cases of suspected TB IRIS. In addition, inadequate or inappropriate TB treatment, other concurrent opportunistic infections, and adverse drug reactions need to be excluded. With regard to unmasking TB IRIS, some residual immune deficiency leading to a new $\mathrm{TB}$ and deterioration of subclinical TB disease may mimic unmasking TB IRIS [124].

Table 2 Common overlapping adverse events of first-line antituberculous drugs and antiretroviral drugs

\begin{tabular}{|c|c|c|c|}
\hline Adverse events & Antituberculous drugs & Antiretroviral drugs & Clinical characteristics \\
\hline Skin reaction [108] & $\begin{array}{l}\text { Rifamycins, isoniazid, pyrazinamide, } \\
\text { ethambutol, streptomycin }\end{array}$ & Nevirapine, efavirenz, abacavir & $\begin{array}{l}\text { Morbilliform rashes, Steven Johnson syn- } \\
\text { drome and toxic epidermal necrolysis, } \\
\text { fixed drug eruption, lichenoid drug } \\
\text { eruptions and acute generalized exan- } \\
\text { thematous pustulosis }\end{array}$ \\
\hline Liver toxicity [109-112] & Rifamycins, isoniazid, pyrazinamide & $\begin{array}{l}\text { Nevirapine, efavirenz, protease inhibi- } \\
\text { tors }\end{array}$ & Transaminitis, cholestatic hepatitis \\
\hline Renal toxicity [113] & Tenofovir & Streptomycin, rifamycins & $\begin{array}{l}\text { Tubulo-interstitial nephritis, proximal } \\
\text { tubulopathy, acute renal failure }\end{array}$ \\
\hline
\end{tabular}




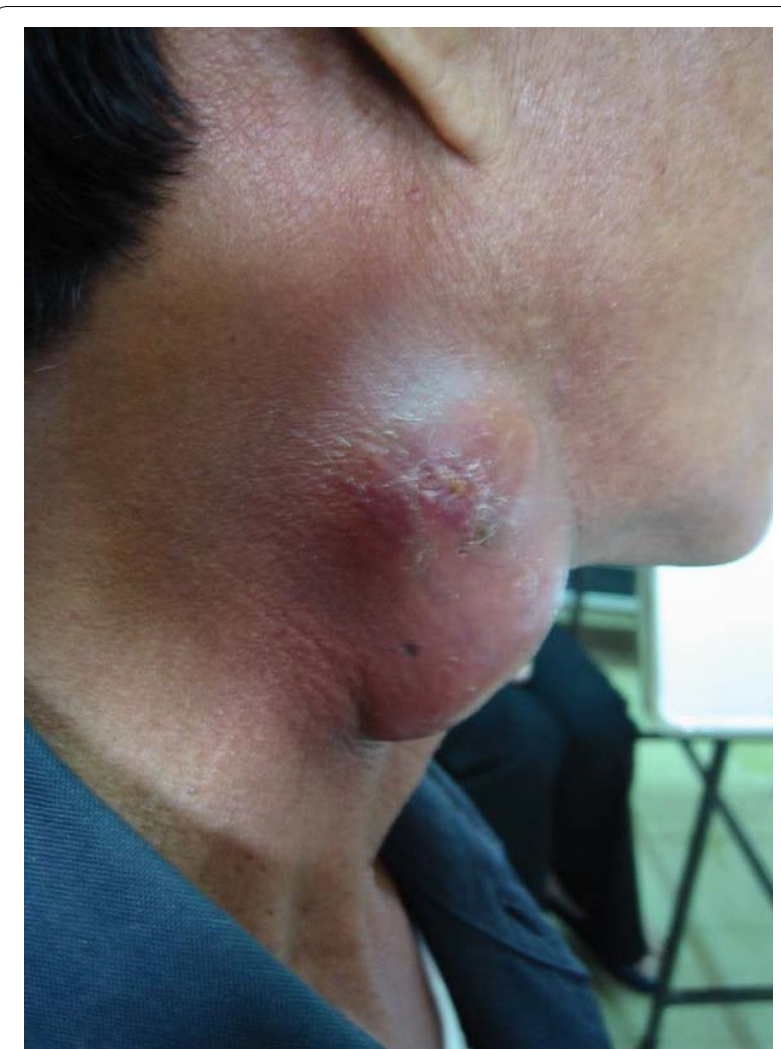

Fig. 1 Paradoxical TB IRIS presenting as worsening of lymph node enlargement

Three major factors involve the pathogenesis of TBIRIS, including (1) mycobacterial antigen burden and anti-TB treatment, (2) immune system function of the patients, and (3) ART initiation and potency. The role of mycobacterial antigen burden is suggested by the risk of TB IRIS that is greater in the patients with earlier ART initiation during TB treatment when the residual mycobacterial load remains high and in those with disseminated TB [124, 130]. Mycobacterial antigen releasing from the killing bacilli with TB treatment stimulates an exuberant inflammatory response. The host immune system also plays roles in the pathogenesis of TB IRIS. Pre-existing immune deficiency has been shown to predispose to TB IRIS. Many previous studies revealed that the low nadir CD4 cell counts have been related to subsequent IRIS $[119,131,132]$. High plasma HIV viral load has been reported to be associated with TB IRIS [133]. In addition, it is associated with an exuberant production of inflammatory cytokines, such as IFN-gamma $[134,135]$. In terms of ART, not only the rate of CD4 cell count recovery in peripheral blood after ART initiation is associated with TB IRIS [115], but the ART may also trigger local immune reconstitution via increased numbers of infiltrating MTB-specific CD4 $+\mathrm{T}$ cells at the site of infection [136].

Most cases of paradoxical TB IRIS are self-limited. When mild paradoxical TB IRIS occurs, symptomatic and supportive treatment can be given, including analgesic drugs, anti-pyretic drugs, and anti-emetic drugs. Local drainage of abscess may be required in some cases. Nonsteroidal anti-inflammatory drugs can be used for those cases in which inflammation or fever cause patients discomfort. Moderate to severe TB IRIS may threaten the clinical status of patients, such as neurologic sequelae from TB of central nervous system and decreased pulmonary function of pulmonary TB IRIS. In such cases, anti-inflammatory treatment should be considered. A randomized control trial showed that prednisolone at $1.5 \mathrm{mg} / \mathrm{kg} /$ day for 2 weeks followed by $0.75 \mathrm{mg} /$ $\mathrm{kg} /$ day for an additional 2 weeks resulted in a reduction of hospitalization and therapeutic procedures [137]. In a case series diagnosed with severe TB IRIS, time to symptom improvement with prednisolone $10-80 \mathrm{mg} /$ day was 3 days [118]. However, adverse effects of corticosteroid treatment should be monitored. ART interruption is not recommended because of increased risk of antiretroviral drug resistance and developing of opportunistic infections. Other potential drugs used to treat TB IRIS are thalidomide, leukotriene receptor antagonists, pentoxifylline, and hydroxychloroquine [138].

\section{Conclusions}

Managing HIV and TB simultaneously is essential to improve patients' survival and quality of life. Integration of care for both HIV and TB using a single facility and a single health care provider is a model to deliver integrated therapy for both diseases and manage adverse drug effects efficiently. Based on the evidence from randomized clinical trials and systemic review, various treatment guidelines have recommended early ART initiation. Integrated therapy is crucial for HIV-infected patients with TB. For TB treatment, a 2-month initial intensive phase of isoniazid, rifampin, pyrazinamide, and ethambutol, followed by 4 months of a continuation phase of isoniazid and rifampin is considered as the standard treatment of drug-susceptible TB. Rifabutin induces CYP3A activity at a lesser magnitude than rifampicin and it may be a more appropriate option for co-administration of many antiretroviral drugs, including PIs. However, rifabutin is not available in many resource-limited countries - where HIV and TB are epidemic.

ART should be initiated in all HIV-infected patients with $\mathrm{TB}$, irrespective of CD4 cell count. The optimal timing to commence ART in HIV-infected patients with TB is within the first 8 weeks of starting antituberculous treatment and within the first 2 weeks for patients who 
have CD4 cell counts less than 50 cells $/ \mathrm{mm}^{3}$. In resourcelimited settings, NNRTI-based ART remains a first-line regimen. A standard dose of efavirenz at $600 \mathrm{mg} /$ day combined with two NRTIs is the recommended regimen in antiretroviral-naïve patients who are receiving rifampicin. A standard dose of nevirapine without leadin could be a safe and acceptable alternative for patients unable to tolerate efavirenz. In the settings where raltegravir is available and accessible, doubling the dose of raltegravir to $800 \mathrm{mg}$ twice daily combined with two NRTIs is recommended. Adverse reactions to either antituberculous or antiretroviral drugs are common in patients receiving integrated therapy. TB IRIS may develop among HIV-infected patients who had recently been diagnosed with active TB, received TB treatment, and subsequently received effective ART. Early recognition and appropriate management of these problems can lead to successful integrated therapy in HIV-infected patients with TB.

\section{Authors' contributions}

WM, SW and SS prepared the original manuscript and contributed to subsequent revisions. All authors read and approved the final manuscript.

\section{Author details}

${ }^{1}$ Department of Disease Control, Ministry of Public Health, Bamrasnaradura Infectious Diseases Institute, Nonthaburi, Thailand. ${ }^{2}$ Division of Infectious Diseases, Department of Medicine, Faculty of Medicine Ramathibodi Hospital, Mahidol University, 270 Rama 6 Road, Bangkok 10400, Thailand.

\section{Competing interests}

The authors declare that they have no competing interests.

Received: 14 March 2016 Accepted: 2 May 2016

Published online: 12 May 2016

\section{References}

1. Mukadi YD, Maher D, Harries A. Tuberculosis case fatality rates in high HIV prevalence populations in sub-Saharan Africa. AIDS. 2001;15:143-52.

2. Zhou J, Elliott J, Li PC, Lim PL, Kiertiburanakul S, Kumarasamy N, et al. Risk and prognostic significance of tuberculosis in patients from the treat Asia HIV observational database. BMC Infect Dis. 2009;9:46.

3. Balcha TT, Skogmar S, Sturegård E, Björkman P, Winqvist N. Outcome of tuberculosis treatment in HIV-positive adults diagnosed through active versus passive case-finding. Glob Health Action. 2015;8:27048.

4. Manosuthi W, Chottanapand S, Thongyen S, Chaovavanich A, Sungkanuparph S. Survival rate and risk factors of mortality among $\mathrm{HIV} /$ tuberculosis-coinfected patients with and without antiretroviral therapy. J Acquir Immune Defic Syndr. 2006;43:42-6.

5. Sungkanuparph S, Manosuthi W, Kiertiburanakul S, Vibhagool A. Initiation of antiretroviral therapy in advanced AIDS with active tuberculosis: clinical experiences from Thailand. J Infect. 2006;52:188-94.

6. Manosuthi W, Chaovavanich A, Tansuphaswadikul S, Prasithsirikul W, Inthong Y, Chottanapund S, et al. Incidence and risk factors of major opportunistic infections after initiation of antiretroviral therapy among advanced HIV-infected patients in a resource-limited setting. J Infect. 2007;55:464-9.

7. Sungkanuparph S, Vibhagool A, Mootsikapun P, Chetchotisakd P, Tansuphaswaswadikul S, Bowonwatanuwong C. Opportunistic infections after the initiation of highly active antiretroviral therapy in advanced
AIDS patients in an area with a high prevalence of tuberculosis. AIDS. 2003;17:2129-31

8. Coker RJ, Hellyer TJ, Brown IN, Weber JN. Clinical aspects of mycobacterial infections in HIV infection. Res Microbiol. 1992;143:377-81.

9. Reid MJ, Shah NS. Approaches to tuberculosis screening and diagnosis in people with HIV in resource-limited settings. Lancet Infect Dis. 2009:9:173-84

10. Cain KP, McCarthy KD, Heilig CM, Monkongdee P, Tasaneeyapan T, Kanara N, et al. An algorithm for tuberculosis screening and diagnosis in people with HIV. N Engl J Med. 2010;362:707-16.

11. Geng E, Kreiswirth B, Burzynski J, Schluger NW. Clinical and radiographic correlates of primary and reactivation tuberculosis: a molecular epidemiology study. JAMA. 2005;293:2740-5.

12. Perlman DC, el-Sadr WM, Nelson ET, Matts JP, Telzak EE, Salomon N, et al. Variation of chest radiographic patterns in pulmonary tuberculosis by degree of human immunodeficiency virus-related immunosuppression. The Terry Beirn Community Programs for Clinical Research on AIDS (CPCRA). The AIDS Clinical Trials Group (ACTG). Clin Infect Dis. 1997;25:242-6.

13. Chaisson RE, Schecter GF, Theuer CP, Rutherford GW, Echenberg DF, et al. Tuberculosis in patients with the acquired immunodeficiency syndrome. Clinical features, response to therapy, and survival. Am Rev Respir Dis. 1987;136:570-4.

14. Greenberg SD, Frager D, Suster B, Walker S, Stavropoulos C, Rothpearl A. Active pulmonary tuberculosis in patients with AIDS: spectrum of radiographic findings (including a normal appearance). Radiology. 1994;193:115-9.

15. Pepper T, Joseph P, Mwenya C, McKee GS, Haushalter A, Carter A, et al. Normal chest radiography in pulmonary tuberculosis: implications for obtaining respiratory specimen cultures. Int J Tuberc Lung Dis. 2008;12:397-403.

16. Chaisson RE, Schecter GF, Theuer CP, Rutherford GW, Echenberg DF, Hopewell PC. Tuberculosis in patients with the acquired immunodeficiency syndrome. Clinical features, response to therapy, and survival. Am Rev Respir Dis. 1987;136:570-4.

17. Rajasekaran S, Mahilmaran A, Annadurai S, Kumar S, Raja K. Manifestation of tuberculosis in patients with human immunodeficiency virus: a large Indian study. Ann Thorac Med. 2007;2:58-60.

18. Jones BE, Young SM, Antoniskis D, Davidson PT, Kramer F, Barnes PF. Relationship of the manifestations of tuberculosis to CD4 cell counts in patients with human immunodeficiency virus infection. Am Rev Respir Dis. 1993;148:1292-7.

19. Shafer RW, Kim DS, Weiss JP, Quale JM. Extrapulmonary tuberculosis in patients with human immunodeficiency virus infection. Medicine. 1991;70:384-97.

20. Török ME, Yen NT, Chau TT, Mai NT, Phu NH, Mai PP, et al. Timing of initiation of antiretroviral therapy in human immunodeficiency virus (HIV)associated tuberculous meningitis. Clin Infect Dis. 2011;52:1374-83.

21. Gray JM, Cohn DL. Tuberculosis and HIV coinfection. Semin Respir Crit Care Med. 2013;34:32-43.

22. Steingart KR, Ng V, Henry M, Hopewell PC, Ramsay A, Cunningham J, et al. Sputum processing methods to improve the sensitivity of smear microscopy for tuberculosis: a systematic review. Lancet Infect Dis. 2006;60:664-74

23. Samb B, Sow PS, Kony S, Maynart-Badiane M, Diouf G, Cissokho S, et al. Risk factors for negative sputum acid-fast bacilli smears in pulmonary tuberculosis: results from Dakar, Senegal, a city with low HIV seroprevalence. Int J Tuberc Lung Dis. 1999;3:330-6.

24. Apers L, Wijarajah C, Mutsvangwa J, Chigara N, Mason P, van der Stuyft P. Accuracy of routine diagnosis of pulmonary tuberculosis in an area of high HIV prevalence. Int J Tuberc Lung Dis. 2004;8:945-51.

25. Zumla A, Raviglione M, Hafner R, von Reyn CF. Tuberculosis. N Engl J Med. 2013;368:745-55.

26. Drobniewski FA, Caws M, Gibson A, Young D. Modern laboratory diag nosis of tuberculosis. Lancet Infect Dis. 2003;3:141-7.

27. Sungkanuparph S, Eampokalap B, Chottanapund S, Thongyen S, Manosuthi W. Impact of drug-resistant tuberculosis on the survival of HIV-infected patients. Int J Tuberc Lung Dis. 2007;11:325-30.

28. Chung-Delgado K, Guillen-Bravo S, Revilla-Montag A, Bernabe-Ortiz A. Mortality among MDR-TB cases: comparison with drug-susceptible tuberculosis and associated factors. PLoS One. 2015;10:e0119332. 
29. World Health Organization. Automated real-time nucleic acid amplification technology for rapid and simultaneous detection of tuberculosis and rifampicin resistance: Xpert MTB/RIF system: policy update. Geneva: World Health Organization; 2013.

30. Scott LE, McCarthy K, Gous N, Nduna M, Van Rie A, Sanne I, et al. Comparison of Xpert MTB/RIF with other nucleic acid technologies for diagnosing pulmonary tuberculosis in a high HIV prevalence setting: a prospective study. PLoS Med. 2011;8:e1001061.

31. Dheda K, Davids V, Lenders L, Roberts T, Meldau R, Ling D, et al. Clinical utility of a commercial LAM-ELISA assay for TB diagnosis in HIV-infected patients using urine and sputum samples. PLoS One. 2010;5(3):e9848.

32. Drain PK, Losina E, Coleman SM, Giddy J, Ross D, Katz JN, et al. Value of urine lipoarabinomannan grade and second test for optimizing clinicbased screening for HIV-associated pulmonary tuberculosis. J Acquir Immune Defic Syndr. 2015;68:274-80.

33. Peter JG, Zijenah LS, Chanda D, Clowes P, Lesosky M, Gina P, et al. Effect on mortality of point-of-care, urine-based lipoarabinomannan testing to guide tuberculosis treatment initiation in HIV-positive hospital inpatients: a pragmatic, parallel-group, multicountry, open-label, randomised controlled trial. Lancet. 2016;387:1187-97.

34. Purohit MR, Mustafa T, Wiker HG, Morkve O, Sviland L. Immunohistochemical diagnosis of abdominal and lymph node tuberculosis by detecting Mycobacterium tuberculosis complex specific antigen MPT64. Diagn Pathol. 2007;2:36.

35. Purohit MR, Mustafa T, Wiker HG, Sviland L. Rapid diagnosis of tuberculosis in aspirate, effusions, and cerebrospinal fluid by immunocytochemical detection of Mycobacterium tuberculosis complex specific antigen MPT64. Diagn Cytopathol. 2012;40:782-91.

36. Denkinger CM, Schumacher SG, Boehme CC, Dendukuri N, Pai M, Steingart KR. Xpert MTB/RIF assay for the diagnosis of extrapulmonary tuberculosis: a systematic review and metaanalysis. Eur Respir J. 2014:44:435-46.

37. Shriner KA, Mathisen GE, Goetz MB. Comparison of mycobacterial lymphadenitis among persons infected with human immunodeficiency virus and seronegative controls. Clin Infect Dis. 1992;15:601-5.

38. Purohit M, Mustafa T. Laboratory diagnosis of extra-pulmonary tuberculosis (EPTB) in resource-constrained setting: state of the art, challenges and the need. J Clin Diagn Res. 2015;9:1-6.

39. Dinnes J, Deeks J, Kunst H, Gibson A, Cummins E, Waugh N, et al. A systematic review of rapid diagnostic tests for the detection of tuberculosis infection. Health Technol Assess. 2007;11:1-196.

40. Blanc FX, Sok T, Laureillard D, Borand L, Rekacewicz C, Nerrienet E, et al. Earlier versus later start of antiretroviral therapy in HIV-infected adults with tuberculosis. N Engl J Med. 2011:365:1471-81.

41. Abdool Karim SS, Naidoo K, Grobler A, Padayatchi N, Baxter C, Gray $A$, et al. Timing of initiation of antiretroviral drugs during tuberculosis therapy. N Engl J Med. 2010;362:697-706

42. Abdool Karim SS, Naidoo K, Grobler A, Padayatchi N, Baxter C, Gray AL, et al. Integration of antiretroviral therapy with tuberculosis treatment. N Engl J Med. 2011;365:1492-501.

43. Havlir DV, Kendall MA, Ive P, Kumwenda J, Swindells S, Qasba SS, et al. Timing of antiretroviral therapy for HIV-1 infection and tuberculosis. N Engl J Med. 2011;365:1482-91.

44. Manosuthi W, Mankatitham W, Lueangniyomkul A, Thongyen S, Likanonsakul S, Suwanvattana P, et al. Time to initiate antiretrovira therapy between 4 weeks and 12 weeks of tuberculosis treatment in HIV-infected patients: results from the TIME study. J Acquir Immune Defic Syndr. 2012;60:377-83.

45. Uthman OA, Okwundu C, Gbenga K, Volmink J, Dowdy D, Zumla A, et al. Optimal timing of antiretroviral therapy initiation for HIV-infected adults with newly diagnosed pulmonary tuberculosis: a systematic review and meta-analysis. Ann Intern Med. 2015;163:32-9.

46. Mfinanga SG, Kirenga BJ, Chanda DM, Mutayoba B, Mthiyane T, Yimer $\mathrm{G}$, et al. Early versus delayed initiation of highly active antiretroviral therapy for HIV-positive adults with newly diagnosed pulmonary tuberculosis (TB-HAART): a prospective, international, randomised, placebo-controlled trial. Lancet Infect Dis. 2014;14:563-71.

47. World Health Organization. Consolidated guidelines on the use of antiretroviral drugs for treating and preventing HIV infection: Recommendations for a public health approach. http://www.who.int/hiv/pub/ guidelines/arv2013/. Accessed 26 Dec 2015.
48. World Health Organisation. WHO global tuberculosis report 2015. http://apps.who.int/iris/bitstream/10665/44165/1/9789241547833_ eng.pdf?ua=1\&ua=1. Accessed 27 Feb 2016.

49. World Health Organization. WHO policy on collaborative TB/HIV activities: Guidelines for national programmes and other stakeholders. http:// www.who.int/tb/publications/2012/tb_hiv_policy_9789241503006/ en/. Accessed 26 Dec 2015.

50. Lawn SD, Campbell L, Kaplan R, Little F, Morrow C, Wood R, et al. Delays in starting antiretroviral therapy in patients with HIV-associated tuberculosis accessing non-integrated clinical services in a South African township. BMC Infect Dis. 2011;11:258.

51. Frasca K, Cohn J. Integration of HIV and tuberculosis in the community. J Int Assoc Provid AIDS Care. 2014;13:534-8.

52. Owiti P, Zachariah R, Bissell K, Kumar AM, Diero L, Carter EJ, et al. Integrating tuberculosis and HIV services in rural Kenya: uptake and outcomes. Public Health Action. 2015;5:36-44.

53. Legido-Quigley H, Montgomery CM, Khan P, Atun R, Fakoya A, Getahun $\mathrm{H}$, et al. Integrating tuberculosis and HIV services in low- and middle-income countries: a systematic review. Trop Med Int Health. 2013;18:199-211.

54. FoxW, Ellard GA, Mitchison DA. Studies on the treatment of tuberculosis undertaken by the British medical research council tuberculosis units, 1946-1986, with relevant subsequent publications. Int J Tuberc Lung Dis. 1999:3(Suppl 2):S231-79.

55. Mitchison D, Davies G. The chemotherapy of tuberculosis: past, present and future. Int J Tuberc Lung Dis. 2012;16:724-32.

56. Singapore Tuberculosis Service, British Medical Research Council. Clinical trial of six-month and four-month regimens of chemotherapy in the treatment of pulmonary tuberculosis: the results up to 30 months. Tubercle. 1981;62:95-102.

57. The Research Committee of the British Thoracic Society. A controlled trial of 6 months' chemotherapy in pulmonary tuberculosis. Final report: results during the 36 months after the end of chemotherapy and beyond. Br J Dis Chest. 1984;78:330-6.

58. World Health Organization. Treatment of tuberculosis: guidelines for national programmes, 4th ed. 2010. http://www.who.int/tb/publications/tb_treatmentguidelines/en/. Accessed 16 Feb 2016.

59. National Collaborating Centre for Chronic Conditions and the Centre for Clinical Practice at NICE. Tuberculosis: clinical diagnosis and management of tuberculosis, and measures for its prevention and control. London: Royal College of Physicians of London; 2011. http://www.nice. org.uk/nicemedia/live/13422/53638/53638.pdf. Accessed 16 Feb 2016.

60. Blumberg HM, Burman WJ, Chaisson RE, Daley CL, Etkind SC, Friedman $\mathrm{LN}$, et al. American thoracic society/centers for disease control and prevention/infectious diseases society of America: treatment of tuberculosis. Am J Respir Crit Care Med. 2003;15(167):603-62.

61. Horsburgh CR Jr, Barry CE 3rd, Lange C. Treatment of tuberculosis. N Engl J Med. 2015;373:2149-60.

62. Gillespie SH, Crook AM, McHugh TD, Mendel CM, Meredith SK, Murray $S R$, et al. Four-month moxifloxacin-based regimens for drug-sensitive tuberculosis. N Engl J Med. 2014;371:1577-87.

63. Jindani A, Harrison TS, Nunn AJ, Phillips PP, Churchyard GJ, Charalambous $\mathrm{S}$, et al. High-dose rifapentine with moxifloxacin for pulmonary tuberculosis. N Engl J Med. 2014;371:1599-608.

64. Merle CS, Fielding K, Sow OB, Gninafon M, Lo MB, Mthiyane T, et al. A four-month gatifloxacin-containing regimen for treating tuberculosis. $N$ Engl J Med. 2014;371:1588-98.

65. Mitchison DA. Role of individual drugs in the chemotherapy of tuberculosis. Int J Tuberc Lung Dis. 2000;4:796-806.

66. Prasad K, Singh MB. Corticosteroids for managing tuberculous meningitis. Cochrane Database Syst Rev. 2008;1:CD002244.

67. Mayosi BM, Ntsekhe M, Volmink JA, Commerford PJ. Interventions for treating tuberculous pericarditis. Cochrane Database Syst Rev. 2002:4:CD000526.

68. Heemskerk AD, Bang ND, Mai NT, Chau TT, Phu NH, Loc PP, et al. Intensified antituberculosis therapy in adults with tuberculous meningitis. N Engl J Med. 2016;374:124-34.

69. Panel on Antiretroviral Guidelines for Adults and Adolescents. Guidelines for the use of antiretroviral agents in HIV-1-infected adults and adolescents. Department of Health and Human Services. http://www. 
aidsinfo.nih.gov/ContentFiles/AdultandAdolescentGL.pdf. Accessed 19 Feb 2016.

70. British HIV Association. British HIV Association guidelines for the treatment of TB/HIV coinfection 2011. HIV Med. 2011;12:517-24

71. Kassim S, Sassan-Morokro M, Ackah A, Abouya LY, Digbeu H, Yesso G, et al. Two-year follow-up of persons with HIV-1-and HIV-2-associated pulmonary tuberculosis treated with short-course chemotherapy in West Africa. AIDS. 1995;9:1185-91.

72. Sterling TR, Alwood K, Gachuhi R, Coggin W, Blazes D, Bishai WR, et al. Relapse rates after short-course (6-month) treatment of tuberculosis in HIV-infected and uninfected persons. AIDS. 1999;13:1899-904.

73. el-Sadr WM, Perlman DC, Matts JP, Nelson ET, Cohn DL, Salomon N, et al. Evaluation of an intensive intermittent-induction regimen and duration of short-course treatment for human immunodeficiency virus-related pulmonary tuberculosis. Terry Beirn Community Programs for Clinical Research on AIDS (CPCRA) and the AIDS Clinical Trials Group (ACTG). Clin Infect Dis. 1998;26:1148-58.

74. Ahmed Khan F, Minion J, Al-Motairi A, Benedetti A, Harries AD, Menzies D. An updated systematic review and meta-analysis on the treatment of active tuberculosis in patients with HIV infection. Clin Infect Dis. 2012;55:1154-63.

75. Ahmad Khan F, Minion J, Pai M, Royce S, Burman W, Harries AD, et al Treatment of active tuberculosis in HIV-coinfected patients: a systematic review and meta-analysis. Clin Infect Dis. 2010;50:1288-99.

76. Aaron L, Saadoun D, Calatroni I, Launay O, Mémain N, Vincent V, et al. Tuberculosis in HIV-infected patients: a comprehensive review. Clin Microbiol Infect. 2004;10:388-98.

77. Naiker S, Connolly C, Wiesner L, Kellerman T, Reddy T, Harries A, et al. Randomized pharmacokinetic evaluation of different rifabutin doses in African HIV-infected tuberculosis patients on lopinavir/ritonavir-based antiretroviral therapy. BMC Pharmacol Toxicol. 2014;15:61.

78. Davies G, Cerri S, Richeldi L. Rifabutin for treating pulmonary tuberculosis. Cochrane Database Syst Rev. 2007:4:CD005159.

79. Jindani A, Nunn AJ, Enarson DA. Two 8-month regimens of chemotherapy for treatment of newly diagnosed pulmonary tuberculosis: international multicentre randomised trial. Lancet. 2004;364:1244-51.

80. Kassahun K, McIntosh I, Cui D, Hreniuk D, Merschman S, Lasseter K, et al. Metabolism and disposition in humans of raltegravir (MK-0518), an antiAIDS drug targeting the human immunodeficiency virus 1 integrase enzyme. Drug Metab Dispos. 2007;35:1657-63.

81. Acosta EP, Kendall MA, Gerber JG, Alston-Smith B, Koletar SL, Zolopa AR, et al. Effect of concomitantly administered rifampin on the pharmacokinetics and safety of atazanavir administered twice daily. Antimicrob Agents Chemother. 2007;51:3104-10.

82. Burger DM, Agarwala S, Child M, Been-Tiktak A, Wang Y, Bertz R. Effect of rifampin on steady-state pharmacokinetics of atazanavir with ritonavir in healthy volunteers. Antimicrob Agents Chemother. 2006;50:3336-42.

83. Justesen US, Andersen AB, Klitgaard NA, Brosen K, Gerstoft J, Pedersen C. Pharmacokinetic interaction between rifampin and the combination of indinavir and low-dose ritonavir in HIV-infected patients. Clin Infect Dis. 2004:38:426-9.

84. Schmitt C, Riek M, Winters K, Schutz M, Grange S. Unexpected hepatotoxicity of rifampin and saquinavir/ritonavir in healthy male volunteers. Arch Drug Inf. 2009;2:8-16.

85. Haas DW, Koletar SL, Laughlin L, Kendall MA, Suckow C, Gerber JG, et al. Hepatotoxicity and gastrointestinal intolerance when healthy volunteers taking rifampin add twice-daily atazanavir and ritonavir. J Acquir Immune Defic Syndr. 2009;50:290-3.

86. Sunpath $\mathrm{H}$, Winternheimer $\mathrm{P}$, Cohen $\mathrm{S}$, Tennant I, Chelin N, Gandhi RT, et al. Double-dose lopinavir-ritonavir in combination with rifampicinbased anti-tuberculosis treatment in South Africa. Int J Tuberc Lung Dis. 2014;18:689-93.

87. Lopez-Cortes LF, Ruiz-Valderas R, Viciana P, Alarcon-Gonzalez A, GomezMateos J, Leon-Jimenez E, et al. Pharmacokinetic interactions between efavirenz and rifampicin in HIV-infected patients with tuberculosis. Clin Pharmacokinet. 2002;41:681-90.

88. Manosuthi W, Sungkanuparph S, Thakkinstian A, Vibhagool A, Kiertiburanakul S, Rattanasiri S, et al. Efavirenz levels and 24-week efficacy in HIV-infected patients with tuberculosis receiving highly active antiretroviral therapy and rifampicin. AIDS. 2005;19:1481-6.
89. Manosuthi W, Kiertiburanakul S, Sungkanuparph S, Ruxrungtham K, Vibhagool A, Rattanasiri S, et al. Efavirenz 600 mg/day versus efavirenz $800 \mathrm{mg} /$ day in HIV-infected patients with tuberculosis receiving rifampicin: 48 weeks results. AIDS. 2006;20:131-2.

90. Boulle A, Van Cutsem G, Cohen K, Hilderbrand K, Mathee S, Abrahams $M$, et al. Outcomes of nevirapine- and efavirenz-based antiretroviral therapy when coadministered with rifampicin-based antitubercular therapy. JAMA. 2008;300:530-9.

91. Manosuthi W, Mankatitham W, Lueangniyomkul A, Chimsuntorn S, Sungkanuparph S. Standard-dose efavirenz vs. standard-dose nevirapine in antiretroviral regimens among HIV-1 and tuberculosis co-infected patients who received rifampicin. HIV Med. 2008;9:294-9.

92. Manosuthi W, Sungkanuparph S, Tantanathip P, Lueangniyomkul A, Mankatitham W, Prasithsirskul W, et al. A randomized trial comparing plasma drug concentrations and efficacies between 2 nonnucleoside reverse-transcriptase inhibitor-based regimens in HIV-infected patients receiving rifampicin: the N2R Study. Clin Infect Dis. 2009;48:1752-9.

93. Kwara A, Tashima KT, Dumond JB, Poethke P, Kurpewski J, Kashuba AD, et al. Modest but variable effect of rifampin on steady-state plasma pharmacokinetics of efavirenz in healthy African-American and Caucasian volunteers. Antimicrob Agents Chemother. 2011;55:3527-33.

94. Gengiah TN, Holford NH, Botha JH, Gray AL, Naidoo K, Abdool Karim SS. The influence of tuberculosis treatment on efavirenz clearance in patients co-infected with HIV and tuberculosis. Eur J Clin Pharmacol. 2012;68:689-95.

95. Manosuthi W, Sukasem C, Lueangniyomkul A, Mankatitham W, Thongyen S, Nilkamhang S, et al. Impact of pharmacogenetic markers of CYP2B6, clinical factors, and drug-drug interaction on efavirenz concentrations in HIV/tuberculosis-coinfected patients. Antimicrob Agents Chemother. 2013;57:1019-24.

96. Uttayamakul S, Likanonsakul S, Manosuthi W, Wichukchinda N, Kalambaheti T, Nakayama EE, et al. Effects of CYP2B6 G516T polymorphisms on plasma efavirenz and nevirapine levels when co-administered with rifampicin in HIV/TB co-infected Thai adults. AIDS Res Ther. 2010;7:8.

97. Ribera E, Pou L, Lopez RM, Crespo M, Falco V, Ocana I, et al. Pharmacokinetic interaction between nevirapine and rifampicin in HIV-infected patients with tuberculosis. J Acquir Immune Defic Syndr. 2001;28:450-3.

98. Ramachandran G, Hemanthkumar AK, Rajasekaran S, Padmapriyadarsini C, Narendran G, Sukumar B, et al. Increasing nevirapine dose can overcome reduced bioavailability due to rifampicin coadministration. J Acquir Immune Defic Syndr. 2006:42:36-41.

99. Manosuthi W, Ruxrungtham K, Likanonsakul S, Prasithsirikul W, Inthong $Y$, Phoorisri T, et al. Nevirapine levels after discontinuation of rifampicin therapy and 60-week efficacy of nevirapine-based antiretroviral therapy in HIV-infected patients with tuberculosis. Clin Infect Dis. 2007;44:141-4.

100. Manosuthi W, Tantanathip P, Chimsuntorn S, Eampokarap B, Thongyen S, Nilkamhang S, et al. Treatment outcomes of patients co-infected with HIV and tuberculosis who received a nevirapine-based antiretroviral regimen: a four-year prospective study. Int J Infect Dis. 2010;14:e1013-7.

101. Bonnet M, Bhatt N, Baudin E, Silva C, Michon C, Taburet AM, et al. Nevirapine versus efavirenz for patients co-infected with HIV and tuberculosis: a randomised non-inferiority trial. Lancet Infect Dis. 2013;13:303-12.

102. Avihingsanon A, Manosuthi W, Kantipong P, Chuchotaworn C, Moolphate S, Sakornjun W, et al. Pharmacokinetics and 48-week efficacy of nevirapine: 400 versus $600 \mathrm{mg}$ per day in HIV-tuberculosis coinfection receiving rifampicin. Antivir Ther. 2008;13:529-36.

103. Kakuda TN, Scholler-Gyure M, Hoetelmans RM. Pharmacokinetic interactions between etravirine and non-antiretroviral drugs. Clin Pharmacokinet. 2011:50:25-39.

104. Wenning LA, Hanley WD, Brainard DM, Petry AS, Ghosh K, Jin B, et al. Effect of rifampin, a potent inducer of drug-metabolizing enzymes, on the pharmacokinetics of raltegravir. Antimicrob Agents Chemother. 2009;53:2852-6.

105. Grinsztejn B, De Castro N, Arnold V, Veloso VG, Morgado M, Pilotto $\mathrm{JH}$, et al. Raltegravir for the treatment of patients co-infected with HIV and tuberculosis (ANRS 12180 Reflate TB): a multicentre, phase 2, non-comparative, open-label, randomised trial. Lancet Infect Dis. 2014;14:459-67.

106. Yee D, Valiquette C, Pelletier M, Parisien I, Rocher I, Menzies D. Incidence of serious side effects from first-line antituberculosis drugs among 
patients treated for active tuberculosis. Am J Respir Crit Care Med. 2003;167:1472-7.

107. Marks DJ, Dheda K, Dawson R, Ainslie G, Miller RF. Adverse events to antituberculosis therapy: influence of HIV and antiretroviral drugs. Int J STD AIDS. 2009;20:339-45.

108. Lehloenya RJ, Dheda K. Cutaneous adverse drug reactions to antituberculosis drugs: state of the art and into the future. Expert Rev Ant Infect Ther. 2012;10:475-86.

109. Shipton LK, Wester CW, Stock S, Ndwapi N, Gaolathe T, Thior I, et al. Safety and efficacy of nevirapine- and efavirenz-based antiretroviral treatment in adults treated for TB-HIV co-infection in Botswana. Int J Tuberc Lung Dis. 2009;13:360-6.

110. Mankhatitham W, Lueangniyomkul A, Manosuthi W. Hepatotoxicity in patients co-infected with tuberculosis and HIV-1 while receiving nonnucleoside reverse transcriptase inhibitor-based antiretroviral therapy and rifampicin-containing anti-tuberculosis regimen. Southeast Asian J Trop Med Public Health. 2011;42:651-8.

111. Sharma SK, Singla R, Sarda P, Mohan A, Makharia G, Jayaswal A, et al. Safety of 3 different reintroduction regimens of antituberculosis drugs after development of antituberculosis treatment-induced hepatotoxicity. Clin Infect Dis. 2010;50:833-9.

112. Yimer $G$, Aderaye $G$, Amogne W, Makonnen $E$, Aklillu E, Lindquist L, et al. Anti-tuberculosis therapy-induced hepatotoxicity among Ethiopian HIV-positive and negative patients. PLoS One. 2008;3:e1809.

113. Kenyon C, Wearne N, Burton R, Meintjes G. The risks of concurrent treatment with tenofovir and aminoglycosides in patients with HIVassociated tuberculosis. South Afr J HIV Med. 2011:12:43-5.

114. van der Plas H, Meintjes G, Schutz C, Goliath R, Myer L, Baatjie D, et al. Complications of antiretroviral therapy initiation in hospitalised patients with HIV-associated tuberculosis. PLoS One. 2013;8:e54145.

115. Cheng SL, Wang HC, Yang PC. Paradoxical response during anti-tuberculosis treatment in HIV-negative patients with pulmonary tuberculosis. Int J Tuberc Lung Dis. 2007:11:1290-5.

116. Manosuthi W, Kiertiburanakul S, Phoorisri T, Sungkanuparph S. Immune reconstitution inflammatory syndrome of tuberculosis among HIVinfected patients receiving antituberculous and antiretroviral therapy. J Infect. 2006;53:357-63.

117. Manosuthi W, Van Tieu H, Mankatitham W, Lueangniyomkul A, Ananworanich J, Avihingsanon A, et al. Clinical case definition and manifestations of paradoxical tuberculosis-associated immune reconstitution inflammatory syndrome. AIDS. 2009;23:2467-71.

118. Breen RA, Smith CJ, Bettinson H, Dart S, Bannister B, Johnson MA, et al. Paradoxical reactions during tuberculosis treatment in patients with and without HIV co-infection. Thorax. 2004:59:704-7.

119. Muller M, Wandel S, Colebunders R, Attia S, Furrer H, Egger M, et al. Immune reconstitution inflammatory syndrome in patients starting antiretroviral therapy for HIV infection: a systematic review and metaanalysis. Lancet Infect Dis. 2010;10:251-61.

120. Marais S, Meintjes G, Pepper DJ, Dodd LE, Schutz C, Ismail Z, et al. Frequency, severity, and prediction of tuberculous meningitis immune reconstitution inflammatory syndrome. Clin Infect Dis. 2013:56:450-60.

121. Marais S, Scholtz P, Pepper DJ, Meintjes G, Wilkinson RJ, Candy S. Neuroradiological features of the tuberculosis-associated immune reconstitution inflammatory syndrome. Int J Tuberc Lung Dis. 2010;14:188-96.

122. Lawn SD, Wood R. Hepatic involvement with tuberculosis-associated immune reconstitution disease. AIDS. 2007;21:2362-3.

123. Michailidis C, Pozniak AL, Mandalia S, Basnayake S, Nelson MR, Gazzard BG. Clinical characteristics of IRIS syndrome in patients with HIV and tuberculosis. Antivir Ther. 2005;10:417-22.

124. Lawn SD, Wilkinson RJ, Lipman MC, Wood R. Immune reconstitution and "unmasking" of tuberculosis during antiretroviral therapy. Am J Respir Crit Care Med. 2008:177:680-5.
125. John L, Baalwa J, Kalimugogo P, Nabankema E, Castelnuovo B, Muhindo $\mathrm{G}$, et al. Response to 'Does immune reconstitution promote active tuberculosis in patients receiving highly active antiretroviral therapy?'. AIDS. 2005;19:2049-50.

126. Lawn SD, Wainwright $\mathrm{H}$, Orrell C. Fatal unmasking tuberculosis immune reconstitution disease with bronchiolitis obliterans organizing pneumonia: the role of macrophages. AIDS. 2009;23:143-5.

127. French MA, Price P, Stone SF. Immune restoration disease after antiretroviral therapy. AIDS. 2004;18:1615-27.

128. Robertson J, Meier M, Wall J, Ying J, Fichtenbaum CJ. Immune reconstitution syndrome in HIV: validating a case definition and identifying clinical predictors in persons initiating antiretroviral therapy. Clin Infect Dis. 2006;42:1639-46.

129. Meintjes G, Lawn SD, Scano F, Maartens G, French MA, Worodria W, et al. Tuberculosis-associated immune reconstitution inflammatory syndrome: case definitions for use in resource-limited settings. Lancet Infect Dis. 2008:8:516-23.

130. Breton G, Duval X, Estellat C, Poaletti X, Bonnet D, Mvondo Mvondo D, et al. Determinants of immune reconstitution inflammatory syndrome in HIV type 1-infected patients with tuberculosis after initiation of antiretroviral therapy. Clin Infect Dis. 2004;39:1709-12.

131. Worodria W, Menten J, Massinga-Loembe M, Mazakpwe D, Bagenda D, Koole $\mathrm{O}$, et al. Clinical spectrum, risk factors and outcome of immune reconstitution inflammatory syndrome in patients with tuberculosisHIV coinfection. Antivir Ther. 2012;17:841-8.

132. Luetkemeyer AF, Kendall MA, Nyirenda M, Wu X, Ive P, Benson CA, et al. Tuberculosis immune reconstitution inflammatory syndrome in A5221 STRIDE: timing, severity, and implications for HIV-TB programs. J Acquir Immune Defic Syndr. 2014:65:423-8

133. Bonnet M, Baudin E, Jani IV, Nunes E, Verhoustraten F, Calmy A, et al. Incidence of paradoxical tuberculosis-associated immune reconstitution inflammatory syndrome and impact on patient outcome. PLoS One. 2013:8:e84585.

134. Bourgarit A, Carcelain G, Martinez V, Lascoux C, Delcey V, Gicquel B, et al. Explosion of tuberculin-specific Th1-responses induces immune restoration syndrome in tuberculosis and HIV co-infected patients. AIDS. 2006;20:F1-7.

135. Narendran G, Andrade BB, Porter BO, Chandrasekhar C, Venkatesan $\mathrm{P}$, Menon $\mathrm{PA}$, et al. Paradoxical tuberculosis immune reconstitution inflammatory syndrome (TB-IRIS) in HIV patients with culture confirmed pulmonary tuberculosis in India and the potential role of IL-6 in prediction. PLoS One. 2013:8:e63541

136. Breen RA, Smith CJ, Cropley I, Johnson MA, Lipman MC. Does immune reconstitution syndrome promote active tuberculosis in patients receiving highly active antiretroviral therapy? AIDS. 2005;19:1201-6.

137. Meintjes G, Wilkinson RJ, Morroni C, Pepper DJ, Rebe K, Rangaka MX, et al. Randomized placebo-controlled trial of prednisone for paradoxical tuberculosis-associated immune reconstitution inflammatory syndrome. AIDS. 2010;24:2381-90.

138. Lai RP, Meintjes G, Wilkinson RJ. HIV-1 tuberculosis-associated immune reconstitution inflammatory syndrome. Semin Immunopathol. 2016;38:185-98

\section{Submit your next manuscript to BioMed Central and we will help you at every step:}

- We accept pre-submission inquiries

- Our selector tool helps you to find the most relevant journal

- We provide round the clock customer support

- Convenient online submission

- Thorough peer review

- Inclusion in PubMed and all major indexing services

- Maximum visibility for your research

Submit your manuscript at www.biomedcentral.com/submit 